\title{
Limited Market Participation, Financial Intermediation, and Consumption Smoothing
}

\author{
Hiroaki Ohno ${ }^{1}$ \\ ${ }^{1}$ School of Economics, Meiji Gakuin University, Tokyo, Japan \\ Correspondence: Hiroaki Ohno, School of Economics, Meiji Gakuin University, Tokyo, Japan. Tel: \\ 81-5421-5342. E-mail: ohno@eco.meijigakuin.ac.jp \\ Received: November 20, 2014 \\ Accepted: Decemberber 17, 2014 Online Published: February 25, 2015 \\ doi:10.5539/ijef.v7n3p36 \\ URL: http://dx.doi.org/10.5539/ijef.v7n3p36
}

\begin{abstract}
This paper examines the role of financial intermediaries to provide desirable deposit contracts in an overlapping generation economy where consumers are exposed to preference shocks and exogenous limited market participation. It is impossible for agents to obtain perfect risk-sharing opportunities in an imperfect secondary market while financial intermediaries can provide intra-generation risk-sharing against limited market participation. In addition, by setting up a saving stage, posterity is able to receive inter-generation risk-sharing and they can perfectly smooth consumption patterns in spite of the existence of preference shocks.
\end{abstract}

Keywords: financial intermediaries, limited market participation, preference shocks, intra- and inter-generation risk sharing

\section{Introduction}

It can be argued that in the aftermath of the Second World War economic reconstruction was largely achieved through bank-based financial systems. Given some economies were market-oriented before the war, the increased reliance on bank financing in the post-war period adds to the difficulties of understanding the factors underlying salient post-war achievements and the economic function of banking institutions. Indeed, as noted by Allen and Gale (1999), there are discrepancies between economies with bank-based financial systems, such as Germany, France, and Japan, among others, and economies with market-oriented financial systems, including the United Kingdom and the United States. It is thus important to assess the economic rationale underlying bank-based financial systems, which can be helpful in discerning it from the market-oriented alternative.

Some pioneering studies suggest that the curvature of utility functions and preference shocks have the potential to explain the significance and effectiveness of financial intermediation. However, it is not clear whether these developments can be fully explained by shifts in agents' utility curvature. In particular, more detailed explanation of the reasons behind the shifts associated with significant preference shocks is also warranted. In light of these theoretical limitations, it is important to examine the effectiveness of financial intermediation in a dynamic setting. This analysis is performed using an overlapping-generations model with imperfect financial markets, where consumers cannot participate in secondary market on an exogenous basis. The issue of that limited market participation in asset markets matters for consumption and asset returns was first discussed by Mankiw and Zeldes (1991), which estimated Euler equations for stockholders and non-stockholders using data from the Panel Study of Income Dynamics. The literature examining the effect of participation constraints includes Allen and Gale (1994); Cao et al. (2005); Vissing-Jorgensen (2002a, 2002b, 2003); Weil (1992); Williamson (1994); etc. These works analyzes the incomplete market participation generated by various factors such as transaction cost and liquidity (Allen \& Gale, 1994; Williamson, 1994), fixed entry cost (Vissing-Jorgensen, 2002b; Weil, 1992) and model uncertainty (Cao et al., 2005), and market participation risk (Ohno, 2009). In particular, this paper focuses the fixed entry cost for simplicity. Thus, this dynamic economic model allows for the assessment of a bank-based financial system with market constraints.

Building upon earlier work by Bryant (1980), the economic model developed by Diamond and Dybvig (1983) explicitly incorporates financial intermediaries in the analysis, and demonstrates their effectiveness. Further contributions to the debate on the comparative merits of bank-based versus market-based financial systems have ensued from these early studies. Using the Diamond and Dybvig model, Jacklin (1987) suggests that it is difficult to demonstrate the effectiveness of financial intermediaries in the absence of restrictions on market 
trading. In other words, allocation through market trading is deemed to be equivalent to distribution by financial intermediaries. The implicit result is that the economic function of financial intermediaries is conditional on the existence of market imperfections and/or incompleteness. However, with reference to the assumptions underlying the Diamond and Dybvig model, Hellwig (1994) draws attention to the limited capacity of financial intermediaries in influencing resource allocation. Focusing on the market risk premium, Hellwig (1994) demonstrates that the importance of financial intermediaries is reduced through the inability to hedge against this class of risk. Diamond (1997) focuses on the participation constraints in market trading and provides evidence that financial intermediaries are effective vehicles for consumption smoothing. However, and as noted earlier, it is arguably more difficult to demonstrate the usefulness of financial intermediaries in the absence of restrictions on market trading. In this context, we examine the dynamic transition from market- to bank-oriented financial systems.

The important issue of whether it is feasible for financial intermediaries to eliminate idiosyncratic risk from the economy was first discussed by Qi (1994) and Dutta and Kapur (1994). A more recent study by Fulghieri and Rovelli (1998) characterizes the welfare properties of steady-state allocation. In particular, they showed that the resource allocation of financial intermediaries is superior to the frictionless market allocation, but in terms of steady state conditions, the equilibrium path is not clear. This point is further discussed in our paper. In addition, these studies have the merit of analyzing the economic dynamics with reference to the risk aversion parameter. They differ from the present study, which is concerned not so much with the characterization of the curvature of the agents' utility function as by the market participation constraints. Allen and Gale (1997) suggest that financial intermediaries are able to provide consumers with intertemporal smoothing in an overlapping-generations model. However, these are subject to constraints related to consumers' access to financial markets. This paper demonstrates, in contrast with the existing literature, that even if consumers are allowed to access financial markets, perfect consumption smoothing is still possible, albeit under participation constraints. Furthermore, the impact of exogenous shocks and relative risk aversion in the dynamic model are also examined given their importance in determining the significance and speed of transition towards bank-oriented financial systems.

The remainder of this paper examines issues related to the elimination of uninsured preference shocks and the transition from a market-oriented to a bank-based financial system. In particular, the objective of this paper is to explore issues related to multistage risk-sharing, which combines intra- and inter-generation risk sharing opportunities. The evidence from the optimization problems suggests that the likelihood of preference shocks and limited market participation provides consumers with an incentive to make a deposit in banks, thereby driving the economy towards a bank-based financial system. The subsequent sections examine the behavior of economic agents with finite horizons. Section II describes the theoretical setting. Section III examines the effects of imperfect market trading. The theoretical impact of financial intermediation is analyzed in Section IV. This section introduces budget constraints into the analysis of financial intermediaries and shows that consumption smoothing is allowed for future generations through a multistage savings/investment process. Section V examines the dynamic effects of the savings/investment process with respect to two important factors. First, the analysis focuses on the impact of exogenous shocks under participation constraints, which permit the economic adjustment towards bank-based financial systems. Second, the importance of relative risk aversion is also considered as it exerts an influence on the dynamic process in line with limited market participation.

\section{The Model}

The model developed in this paper is an extension of that proposed in Diamond (1997). Time is discrete and indexed by $t \in[0, \ldots, \infty]$. We consider an infinite sequence of three-period overlapping generations.

In this model, only goods that agents can consume or invest in exist. There are two assets available, represented by a long-term asset and a short term asset. If agents invest one unit of endowment in the long-term asset in period $t$ agents can obtain $R$ units of consumption goods in period $t+2$. If agents invest one unit of endowment in the short-term asset in period $t$, agents can obtain $r$ units of consumption goods in period $t+1$. The relationship between short term and long-term returns is assumed to be $1<r^{2}<R$. Hence, if agents successively invest in the short-term asset, they would not gain a return on the long-term asset. Suppose also that investment in the long-term asset is irreversible.

There exist only new generations in period 0 (Note 1). The number of identical new generations is a continuum and normalized to one. In period 1, new generations with identical characteristics come into this economy. In each subsequent period a new generation is added. Information regarding an agent's type, which is available to anyone, is assumed to be given at the end of period $t$ of each $t$-generation, that is, the information about an 
agent's type is symmetrical for all of economic agents (Note 2). All types of $t$-generations are denoted by $(\alpha, t),(\beta, t)$, and $(\gamma, t) .(\alpha, t)$ are early consumers who consume in period $t+1 .(\beta, t)$ and $(\gamma, t)$ are later consumers who consume in period $t+2$. The distinction between type- $\beta$ and type- $\gamma$ is whether or not they can participate in the secondary market, that is, type- $\beta$ can trade with type- $\alpha$, but type- $\gamma$ cannot trade assets with anyone. Using some theoretical basis, Some works tried to explain the reason why such a consumer exists (e.g., Allen \& Gale, 1994; Cao et al., 2005; Vissing-Jorgensen, 2002b; Williamson, 1994; Weil, 1992). In appreciation of theirs contribution, we interpret type- $\gamma$ consumers as facing the infinite transactions costs for simplicity.

Assume that each type's probability of belonging to a particular t-generation is given by $\left(q_{\alpha t}, q_{\beta t}, q_{\gamma t}\right)$, and this probability distribution satisfies the following properties: $q_{\alpha t}+q_{\beta t}+q_{\gamma t}=1$, and $q_{\alpha t}>0, q_{\beta t}>0, q_{\gamma t} \geq$ 0 . These probability values are constant over time, that is, $q_{t} \equiv q \in \mathcal{R}_{+}^{3}$. Suppose that new generations do not know what their own type will be in the future, but they are aware of the probability distribution. Hence, the risks of consumers originate from the types of agents. Assume that the new generations have the following expected utility:

$$
U\left(c_{\alpha t}, c_{\beta t}, c_{\gamma t}\right)=q_{\alpha} \ln c_{\alpha t}+q_{\beta} \ln c_{\beta t}+q_{\gamma} \ln c_{\gamma t} .
$$

In this case, the measure of relative risk aversion parameter is assumed to be equal to one, that is, $-c u^{\prime \prime} / u^{\prime}=1$. We define the value function of any generation as $W t$ and the welfare function of this economy as $W$. The definition of value function and welfare function are as follows:

$$
\begin{aligned}
& W_{t} \equiv U\left(c_{\alpha t}, c_{\beta t}, c_{\gamma t}\right), \\
& W \equiv \lim _{T \rightarrow \infty} \frac{1}{T+1} \sum_{t=0}^{T} W_{t} .
\end{aligned}
$$

We treat all generations comparably.

\section{Limited Market Participation}

In this section, we analyze the consumers' optimization problem and market equilibrium. In the absence of financial intermediaries, agents have to make deals with other agents.

\subsection{Consumers' Optimization}

At first, new generations have assets for the future upon their arrival in the economy. New generations purchase $\epsilon \in[0,1]$ units of short-term assets, and $(1-\epsilon)$ units of long-term assets. However, after learning one's type, for any $(\alpha, t)$ long-term assets are wasted, because of the limited prospects of living until maturity. So, $(\alpha, t)$ sell long-term assets for market participants $(\beta, t)$ and buy additional short-term assets from them. On the other hand, $(\beta, t)$ would be interested in investing in long-term assets using short-term assets, because the latter can live three periods and the return from long-term assets is superior to the return on short-term assets. Hence, after their types are known, $(\alpha, t)$ and $(\beta, t)$ trade with each other using their own assets. We define the assets' future price as $P_{R}$ and $P_{r}$, where $P_{R}$ and $P_{r}$ represent the future price of long-term assets and short-term assets, respectively. Each new generation faces the following problem:

$$
\begin{gathered}
\operatorname{Max} U\left(c_{\alpha t}, c_{\beta t}, c_{\gamma t}\right) \\
\text { s.t. } c_{\alpha t}=\left[\epsilon+(1-\epsilon) \frac{P_{R}}{P_{r}}\right] r, c_{\beta t}=\left[\epsilon \frac{P_{r}}{P_{R}}+(1-\epsilon)\right] R, c_{\gamma t}=\epsilon r^{2}+(1-\epsilon) R .
\end{gathered}
$$

As our assumption ensures interior solution, the first-order condition is the following:

$$
\frac{q_{\alpha} r\left(1-\frac{P_{R}}{P_{r}}\right)}{\left[\epsilon+(1-\epsilon) \frac{P_{R}}{P_{r}}\right] r}+\frac{q_{\beta} R\left(\frac{P_{r}}{P_{R}}-1\right)}{\left[\epsilon \frac{P_{r}}{P_{R}}+(1-\epsilon)\right] R}+\frac{q_{\gamma}\left(r^{2}-R\right)}{\epsilon^{2}+(1-\epsilon) R}=0 .
$$

The following subsection examines the market equilibrium.

\subsection{Market Equilibrium}

Once the agent's type is known, it is possible to trade dispensable assets. $(\alpha, t)$ purchase short-term assets using long-term assets, that is, $(\alpha, t)$ buying $(1-\epsilon) P_{R} / P_{r}$ units of short-term assets. Correspondingly, $(\beta, t)$ purchase $\epsilon P_{r} / P_{R}$ units of long-term assets. On the other hand, $(\beta, t)$ offer $q_{\beta} \epsilon$ units of short-term assets. Hence, in per capita terms, $(\alpha, t)$ can obtain $q_{\beta} \epsilon / q_{\alpha}$ units of short-term assets. In the same way, in per capita terms $(\beta, t)$ can obtain $q_{\alpha}(1-\epsilon) / q_{\beta}$ units of long-term assets. Thus, in equilibrium, the following clearing condition is satisfied:

$$
q_{\alpha}(1-\epsilon) P_{R}=q_{\beta} \epsilon P_{r}
$$

We define $P_{R} / P_{r}$ as $P$. Thus, the consumers' optimization problem is solved by control variable $\epsilon$. This market 
equilibrium $\left\{c^{M}, p^{M}\right\}$ is as follows, where superscript $M$ denotes the market equilibrium:

$$
\left\{c_{\alpha, t}^{M}, c_{\beta t}^{M}, c_{\gamma t}^{M}, P^{M}\right\}=\left\{\frac{q_{\alpha}+q_{\beta}}{q_{\alpha}} \zeta r, \frac{q_{\alpha}+q_{\beta}}{q_{\beta}}(1-\zeta) R, \zeta r^{2}+(1-\zeta) R, \frac{q_{\beta} \zeta}{q_{\alpha}(1-\zeta)}\right\}
$$

where $\zeta=\frac{\phi-\sqrt{\phi^{2}-\frac{4 q_{\alpha} R}{R-r^{2}}}}{2}$ and $\phi=\left(\mathrm{q}_{\alpha}+q_{\gamma}\right)+\left(q_{\alpha}+q_{\beta}\right) \frac{R}{R-r^{2}}$.

Accordingly, when agents are forced to operate within market participation constraints, market equilibrium can be described as above. The following section examines the role of financial intermediaries and shows that such intermediaries are effective vehicles for consumption smoothing.

\section{The Role of Financial Intermediaries}

In this section, it is assumed that monopolistic financial intermediaries infinitely and exclusively engage in the allocation of resources for social welfare. It can then be demonstrated that financial intermediaries provide the opportunity for within-generation risk sharing for consumers as a benchmark for resource allocation (Note 3). Furthermore, it can be shown that on the basis of within-generation risk sharing, financial intermediaries can provide intergeneration risk sharing for consumers.

\subsection{Intra-Generation Risk Sharing}

This subsection analyses within-generation risk sharing. If financial intermediaries provide intra-generation risk sharing, consumers can consume as if they were trading with all other consumers without participation constraints (Note 4). Consequently, the social planner's problem for any generation can be solved by the following:

$$
\begin{gathered}
\operatorname{Max} U\left(c_{\alpha t}, c_{\beta t}, c_{\gamma t}\right) \\
\text { s.t. } \frac{q_{\alpha} c_{\alpha t}}{r}+\frac{q_{\beta} c_{\beta t}+q_{\gamma} c_{\gamma t}}{R}=1 .
\end{gathered}
$$

The financial intermediaries maximize the utility function of any new generations under the budget constraint that endowments are invested in short-term assets as well as in long-term assets. Thus, the following first-order condition can be obtained:

$$
\frac{c_{a t}^{*}}{r}=\frac{c_{\beta t}^{*}}{R}=\frac{c_{y t}^{*}}{R}
$$

Substituting the equation (7) into the budget constraint (6), we can obtain the optimal allocation $\left(c_{\alpha t}^{*}, c_{\beta t}^{*}, c_{\gamma t}^{*}\right)=$ $(r, R, R)$ for any generations, where superscript * represents intra-generation risk sharing. Thus, financial intermediation dissolves the participation constraints (Note 5).

\subsection{Inter-Generation Risk Sharing}

So far, conditional upon the participation constraints, the relational expression, $W_{t}^{M}<W_{t}^{*}$, is satisfied. With the definition of the welfare function of this economy, solving the same problem for each generation satisfies the following relationship: $W^{M}<W^{*}$.

Using this condition, this section examines the feasibility of intergeneration risk sharing suggested by Allen and Gale (1997). In previous sections, market trading and intra-generation risk sharing could not eliminate uninsured idiosyncratic risk, that is, consumers do not have the means for hedging against an early death because in this economy the return on using short-term assets is less than the return on long-term assets. Hence, this economy has relative scarcity of goods. We refer to this condition as uninsured idiosyncratic risk. If financial intermediaries put all endowments into long-term assets at the beginning of this economy, financial intermediaries can obtain $\mathrm{R}$ units of consumption goods at $t=2$ and allocate $q_{\alpha} R$ units for $(\alpha, 1)$ and $\left(q_{\beta}+q_{\gamma}\right) R$ units for $(\beta, 0)$ and $(\gamma, 0)$. All of the following generations, except for the initial generation $(\alpha, 0)$, can consume $R$ units of goods. However, the initial generations have no incentive to delegate endowments because of zero consumption when they are found to be early consumers. Consequently, this policy does not improve the economy in terms of Pareto efficiency. Therefore, the economy is divided into two stages. In the first stage, financial intermediaries save the goods for realization of intergeneration risk sharing. In the second stage, financial intermediaries provide intergeneration risk sharing for all subsequent generations.

\subsection{Saving Stage}

For the feasibility of intergeneration risk sharing, financial intermediaries must accumulate goods. Hence, our focal point is the feasibility of saving by financial intermediaries. If financial intermediaries cannot provide for the above-mentioned market distribution, consumers do not have incentive to make a deposit using their 
endowments. Given this, the following allocation must be satisfied, $\left\{c^{S}\right\}$, where superscript $\mathrm{S}$ stands for the saving stage:

$$
\begin{gathered}
\left\{c^{S}\right\} \equiv \operatorname{argmin} U\left(c_{\alpha t}, c_{\beta t}, c_{\gamma t}\right) \\
\text { s.t. } W_{t}^{M} \leq U\left(c_{\alpha t}, c_{\beta t}, c_{\gamma t}\right) \leq W_{t}^{R}, \frac{c_{\alpha}}{c_{\beta}}=\frac{r}{R}, \text { and } c_{\beta}=c_{\gamma} .
\end{gathered}
$$

These restrictions express the feasibility of budget constraint of financial intermediaries. If financial intermediaries bring consumers $\left\{\mathrm{c}^{\mathrm{s}}\right\}$, consumers are indifferent between managing themselves and delegating this to the financial intermediary. Hence, we define the deposit contract $\left\{d_{E}, d_{L}, d_{L}\right\}$, where subscripts $\mathrm{E}$ and $\mathrm{L}$ denote, respectively, the early consumers (type- $\alpha$ ) and the later consumers (type- $\beta$ and $\gamma$ ). This deposit contract satisfies the following condition:

$$
\{d\} \equiv\left\{\left(d_{E}, d_{L}, d_{L}\right) \mid c_{\alpha}^{S}<d_{E}<r, d_{L}=d_{E} \frac{R}{r}\right\} .
$$

If there are no participation constraints, it is impossible for consumers to obtain deposit contract $\{d\}$. Accordingly, and conditional upon the participation constraints, financial intermediaries can provide this deposit for consumers, whereas consumers place deposits because of the assumption of monotonically increasing utility. Additionally, it is possible for financial intermediaries to save for intergeneration risk sharing. At the beginning of this economy, if financial intermediaries bring consumers the deposit contract $\{d\}$, consumers deposit their endowment. Moreover, financial intermediaries put $q_{\alpha} d_{E} / r$ units of endowment into short-term assets for early consumers and the rest into long-term assets for later consumers and saving. More specifically, financial intermediaries have the following resources $K$ in period 2:

$$
\begin{aligned}
K_{2}( & \equiv \sigma)=R\left(1-q_{\alpha} \frac{d_{E}}{r}\right)-\left(q_{\beta} d_{L}+q_{\gamma} d_{L}\right) \\
& =R\left(1-\frac{d_{E}}{r}\right) .
\end{aligned}
$$

Sequentially, financial intermediaries can save $\sigma$ units of goods per period for newcomers. Up until the last period of saving $q_{\alpha} R$ units of consumption goods, financial intermediaries put resources only into long-term assets. Consequently, given that financial intermediaries have adequate savings in period $t=3$, they then have the following resources available:

$$
K_{3}=r \sigma+\sigma .
$$

Correspondingly, financial intermediaries have $K_{4}=R \sigma+r \sigma+\sigma$ units of saving at $t=4$. In this manner, financial intermediaries can obtain the following saving in period $t=n$ :

$$
K_{n}=\left\{\begin{array}{cc}
0 & \text { if } n=0,1 \\
\frac{R^{\frac{n-2}{2}}(r+R)-r-1}{R-1} \sigma & \text { if } n(\geq 2) \text { is even number } \\
\frac{R^{\frac{n-1}{2}(1+r)-r-1}}{R-1} \sigma \text { if } n(\geq 3) \text { is odd number }
\end{array}\right.
$$

the function $K_{n}$ is increasing and convex in $n$, that is, $K_{n}$ diverges infinitely as $n \rightarrow \infty$. If financial intermediaries accumulate $\widehat{k_{n}}\left(\geq q_{\alpha} R\right)$ units of saving, they have an option to conclude the saving stage (Note $6)$.

\subsection{Consumption Smoothing}

Thus far, if financial intermediaries recommend to consumers the deposit contract $\{d\}$, financial intermediaries can save for intergeneration risk sharing. By the end of the saving stage, total savings are $\widehat{k_{n}} \geq q_{\alpha} R$ units. Based on this saving, it is feasible for financial intermediaries to provide intergeneration risk sharing opportunity. Financial intermediaries can provide $\widehat{k_{n}}$ for early consumers of $n-1$ generations. For this reason, $n-1$ generations can obtain $R$ units of consumption goods regardless of type. Hence, consumers are willing to put their endowments into financial intermediaries, and the following consumers can obtain $\mathrm{R}$ units of consumption goods. Subject to participation constraints, the first stage is a finite horizon. The following periods of intergeneration risk sharing continue into infinity. As in our definition of the welfare function in this economy, financial intermediaries weigh all generations equally. This is expressed by the following relationship of $W_{t}^{S}$ and $W_{t}^{I}$, where superscript $S$ and $I$ denote saving stage and intergeneration risk sharing, respectively:

$$
W \equiv \lim _{T \rightarrow \infty} \frac{1}{T+1} \sum_{t=0}^{T} W_{t}
$$




$$
=\frac{1}{n-1} \sum_{t=0}^{n-2} W_{t}^{S}+\lim _{T \rightarrow \infty} \frac{1}{T-n+2} \sum_{t=n-1}^{T} W_{t}^{I} \rightarrow W^{I} .
$$

Hence, this economy converges to the conditions of intergeneration risk sharing. Here, we can obtain the following proposition:

\section{Proposition (Consumption Smoothing).}

If financial intermediaries provide intergeneration risk sharing for consumers under the strictly positive degree of limited market participation, this economy converges to the condition of removing uninsured preference shocks.

\section{Discussions}

This section numerically examines the relation between saving $\sigma$ and relative risk aversion $\psi$. Previously the utility function of each new generation has been assumed to be the logarithm utility function in which relative risk aversion equals one. Our interest is that there exist other factors in addition to participation constraints in terms of the advantage of saving by financial intermediaries. In particular, our focus is on the curvature of the utility function. Assume that each new generation has the following constant relative risk aversion (CRRA) utility (Note 7):

$$
u(c)=\frac{c^{1-\psi}-1}{1-\psi} \text { where } \psi>1 \text {. }
$$

In case of $\psi=2$, the amount of saving of financial intermediation, that is $\sigma$, is about 0.0071 while $\sigma=$ 0.014 when $\psi=10$ (Note 8). A decrease in the relative risk aversion $\psi$ implies longer saving stages $n$. Hence, it is possible to demonstrate that intermediaries' ample saving derives from the curvature of the consumers' utility functions.

\section{Conclusion}

Financial intermediaries should provide intergeneration risk sharing in a world with symmetric information under the condition of participation constraints. As discussed, Germany, France, Japan, and a number of other countries have bank-based financial systems. If such countries acquire the benefits of intergeneration risk sharing, it is due to their inheritance from past generations. With regard to the transition from a market-based system to a bank-based system, it is possible to imagine the following situation. An exogenous shock then occurs, such as a war or a large-scale economic disaster. The government then has to rebuild as rapidly as possible using a bank-based system, even if this economy was once a market-based system.

Throughout this paper, we have treated financial intermediaries as exclusive institutions and just like social planners. If we extend our scenario to competitive financial intermediaries, it is impossible to save goods because even though some financial intermediaries do not provide within-generation risk sharing for consumers with an eye on future generations, other financial intermediaries do, so rational consumers make a choice regarding the allocation of within-generation risk sharing (Note 9). For this reason, the allocation of competitive equilibrium is intra-generation risk sharing. Hence, if the government takes optimal advantage of the bank-based system, it must regulate a deposit contract for the duration of the saving stage. In fact, the opportunity to provide risk sharing is not only a deposit contract and a contract of insurance by financial intermediaries, but is also a pension, social security, or the like. In the context of this paper, perhaps we should refer to intra-generation risk sharing and intergeneration risk sharing as funded pension and health insurance, respectively.

Also, a large number of R\&D investments require the long-term period. If consumers are assumed to incur the risk of early death and the limited market participation, they may not make a very long-term investment. In case of inter-generation risk sharing, monopolistic financial intermediation is able to provide sufficient long-term capital for business organization. Therefore, such a role of intermediation may ensure stable growth of developing countries. The paper sheds light on the possibility of financial intermediaries for long-term investment and economic growth in comparison with imperfect market.

\section{Acknowledgments}

I am very grateful to Yuichi Fukuta, Yuzo Honda, Shinsuke Ikeda, Nabil Maghrebi, Hiroshi Nakaota, Kazuhiko Nishina, Takayuki Ogawa, Masamitsu Ohnishi, Yoshiro Tsutsui. This research is financially supported by the Grants-in-Aid for Scientific Research for Young Scientists No. 25780206, JSPS, Japan.

\section{References}

Allen, F., \& Gale, D. (1994). Limited Market Participation and Volatility of Asset Prices. American Economic Review, 84, 933-955. 
Allen, F., \& Gale, D (1997). Financial Markets, Intermediaries, and Intertemporal Smoothing. Journal of Political Economy, 105, 523-546. http://dx.doi.org/10.1086/262081

Allen, F., \& Gale, D. (1999). Comparing Financial Systems. Cambridge: MIT Press.

Bhattacharya, S., Fulghieri, P., \& Rovelli, R. (1998). Financial Intermediation Versus Stock Markets in a Dynamic Intertemporal Model. Journal of Institutional and Theoretical Economics, 154, 291-319. http://www.jstor.org/stable/40752063

Bryant, J. A. (1980). Model of Reserves, Bank Runs, and Deposit Insurance. Journal of Banking and Finance, 4, 335-344. http://dx.doi.org/10.1016/0378-4266(80)90012-6

Cao, H. H., Wang, T., \& Zhang, H. H. (2005). Model Uncertainty, Limited Market Participation and Asset Prices. Review of Financial Studies, 18, 1219-1251. http://dx.doi.org/10.1093/rfs/hhi034

Diamond, D., \& Dybvig, P. (1983). Bank Runs, Deposit Insurance, and Liquidity. Journal of Political Economy, 91, 401-419. http://dx.doi.org/10.1086/261155

Diamond, D. (1997). Liquidity, Banks, and Markets. Journal of Political Economy, 105, 928-956. http://dx.doi.org/10.1086/262099

Dutta, J., \& Kapur, S. (1998). Liquidity Preference and Financial Intermediation. Review of Economic Studies, 65, 551-572. http://dx.doi.org/10.1111/1467-937X.00057

Fulghieri, P., \& Rovelli, R. (1998). Capital markets, financial intermediaries, and liquidity supply. Journal of Banking and Finance, 22, 1157-1179. http://dx.doi.org/10.1016/S0378-4266(98)00053-3

Hellwig, M. (1994). Liquidity Provision, Banking, and the Allocation of Interest Rate Risk. European Economic Review, 38, 1363-1389. http://dx.doi.org/10.1016/0014-2921(94)90015-9

Jacklin, C. (1987). Demand Deposits, Trading Restrictions, and Risk-Sharing. In E. C. Prescott, \& N. Wallace (Eds.), Contractual Arrangements for Intertemporal Trade (pp. 26-47). Minneapolis: University of Minnesota Press.

Mankiw, N. G., \& Zeldes, S. P. (1991). The Consumption of Stockholders and Nonstockholders. Journal of Financial Economics, 29, 97-112. http://dx.doi.org/10.1016/0304-405X(91)90015-C

Ohno, H. (2009). Incomplete Market Participation, Endogenous Endowment Risks and Welfare. Journal of Economics and Business, 61, 392-403. http://dx.doi.org/10.1016/j.jeconbus.2009.02.002

Qi, J. (1994). Bank Liquidity and stability in an Overlapping Generations Model. Review of Financial Studies, 7 , 389-417. http://dx.doi.org/10.1093/rfs/7.2.389

Vissing-Jorgensen, A. (2002a). Limited Asset Market Participation and the Elasticity of Intertemporal Substitution. Journal of Political Economy, 110, 825-853. http://dx.doi.org/10.1086/340782

Vissing-Jorgensen, A. (2002b). Towards an Explanation of Household Portfolio Choice Heterogeneity: Nonfinancial Income and Participation Cost Structures (No. w8884). National Bureau of Economic Research.

Vissing-Jorgensen, A., \& Attanasio, O. P. (2003). Stock Market Participation, Intertemporal Substitution and Risk Aversion. American Economic Review, 93, 383-391. http://dx.doi.org/10.1257/000282803321947399

Weil, P. (1992). Hand-to-mouth Consumers and Asset Prices. European Economic Review, 36, 575-583. http://dx.doi.org/10.1016/0014-2921(92)90115-D

Williamson, S. (1994). Liquidity and Market Participation. Journal of Economic Dynamics and Control, 18, 629-670. http://dx.doi.org/10.1016/0165-1889(94)90026-4

\section{Notes}

Note 1. Generally, when using an overlapping generations model, all generations exist at the beginning of the economy. To focus on intra-generation risk sharing and inter-generation risk sharing in contrast to market trading, however, we use this ad-hoc setting.

Note 2. In this paper, we assume perfect information and so the information on agents is generated successively. Hence, all of this economic agents share the same information at any time. This implies that if financial intermediaries lack information about agents, they will be unable to distribute optimum allocations and our conclusions will not hold. 
Note 3. In a complete market, perfect risk sharing is attained through market trading, but in our setting this situation is not attained because of the existence of type $(\gamma, t)$. Financial intermediaries can provide intrageneration risk sharing in our setting, but we consider the "benchmark" case because the purpose of this section is to focus on the elimination of uninsured idiosyncratic risk, that is, perfect consumption smoothing.

Note 4. Proof of this lemma is provided in the Appendix.

Note 5. See Appendix.

Note 6. Financial intermediation could secure ever-increasing investment payoff over time by saving a little bit more each period. Hence, if they will not stop accumulating assets at pay off, the payoff diverges to infinity. However, the deposit contract represents the provision of a fixed-point payoff. We only show one of many possible dynamic equilibria paths. Additionally, impatient financial intermediaries should have provided the only within-generation risk sharing.

Note 7. See Diamond and Dybvig (1983) concerning the assumption of relative risk aversion parameters larger than one. Note that agents do not have the incentive for consumption smoothing when relative risk aversion parameters are smaller than unity.

Note 8. As an additional assumption, the probability of type is stabilized $\left(q_{\alpha}, q_{\beta}, q_{\gamma}\right)=(0.1,0.4,0.5)$.

Note 9. This statement is based on the analysis of Dutta and Kapur (1998, Theorem, p. 7).

\section{Appendix A}

\section{Derivation of $\epsilon^{*}$}

1. Under the condition of non-participation constraints.

Assuming $q_{\gamma}=0$, we can solve problem (2) in a straightforward manner:

$$
\begin{gathered}
\frac{q_{\alpha} r\left(1-\frac{P_{R}}{P_{r}}\right)}{\left[\epsilon+(1-\epsilon) \frac{P_{R}}{P_{r}}\right] r}+\frac{q_{\beta} R\left(\frac{P_{r}}{P_{R}}-1\right)}{\left[\epsilon \frac{P_{r}}{P_{R}}+(1-\epsilon)\right] R}=0 \\
\frac{P_{R}}{P_{r}}=\frac{q_{\beta} \epsilon}{q_{\alpha}(1-\epsilon)}
\end{gathered}
$$

Solving the above equation, the investment ratio $\zeta$ equals the probability of early consumers $q_{\alpha}$. Then the frictionless allocation is $\left(c_{\alpha}, c_{\beta}\right)=(r, R)$.

Note that this allocation equals the allocation of within-generation risk sharing, that is, financial intermediaries do not get an edge in the trading market. Hence, financial intermediaries cannot carry out intergeneration risk sharing because of the impossibility of saving. Thus the following lemma is obtained.

Lemma 1 (Full participation economy, Dyamond \& Dybvig, 1983).

If there are no participation constraints, financial intermediaries cannot save commodity goods. Hence, it is impossible to provide intergeneration risk sharing.

2. Under the condition of participation constraints

Cleaning up $\epsilon$ in consumer optimization problem (2), the following relation is satisfied:

$$
\frac{q_{\alpha} r\left[1-\frac{q_{\beta} \epsilon}{q_{\alpha}(1-\epsilon)}\right]}{\frac{q_{\alpha}+q_{\beta}}{q_{\alpha}} \epsilon r}+\frac{q_{\beta} R\left[\frac{q_{\alpha}(1-\epsilon)}{q_{\beta} \epsilon}-1\right]}{\frac{q_{\alpha}+q_{\beta}}{q_{\beta}}(1-\epsilon) R}+\frac{q_{\gamma}\left(r^{2}-R\right)}{\epsilon r^{2}+(1-\epsilon) R}=0
$$

Hence, calculating the above expression, $\epsilon *$ can be characterized as Eq. (5).

\section{Appendix B}

Proof of $W^{M} \leq W^{*}$

The calculus in this proof is based on the comparison of budget constraints of two optimization problems. The case of market trading with limited market participation is described as Eq. (2). Also, equilibrium condition requires Eq. (4). A case of intra-generation risk sharing is characterized by Eq. $\left(c_{\alpha t}^{*}, c_{\beta t}^{*}, c_{\gamma t}^{*}\right)=(r, R, R)$. If 
financial intermediaries allocate $\left\{c^{M}\right\}$ to consumers, the following equation is satisfied:

$$
\frac{1}{r}\left\{q_{\alpha}\left[\epsilon+(1-\epsilon) \frac{P_{R}}{P_{r}}\right] r\right\}+\frac{1}{R}\left\{q_{\beta}\left[\epsilon \frac{P_{r}}{P_{R}}+(1-\epsilon)\right] R+q_{\gamma}\left[\epsilon r^{2}+(1-\epsilon) R\right]\right\}
$$

If we substitute the equilibrium condition $P^{M}$, we can obtain the following relation:

$$
q_{\alpha}+q_{\beta}+q_{\gamma}\left[1+\left(\frac{r^{2}}{R}-1\right) \epsilon\right] \leq q_{\alpha}+q_{\beta}+q_{\gamma}(=1)
$$

Hence, if financial intermediaries provide a market allocation for consumers, financial intermediaries can leave over resources. Consequently, a monotonic increase in the utility function implies the following relationship: $W^{M} \leq W^{*}$.

\section{Copyrights}

Copyright for this article is retained by the author(s), with first publication rights granted to the journal.

This is an open-access article distributed under the terms and conditions of the Creative Commons Attribution license (http://creativecommons.org/licenses/by/3.0/). 